Board of Governors of the Federal Reserve System

International Finance Discussion Papers

Number 1300

September 2020

\title{
Investor Sentiment and the (Discretionary) Accrual-return Relation
}

\author{
Jiajun Jiang, Qi Liu, Bo Sun
}

Please cite this paper as:
Jiang, Jiajun, Qi Liu, Bo Sun (2020). "Investor Sentiment and the (Discretionary) Accrual-
return Relation," International Finance Discussion Papers 1300. Washington: Board of
Governors of the Federal Reserve System, https://doi.org/10.17016/IFDP.2020.1300.

NOTE: International Finance Discussion Papers (IFDPs) are preliminary materials circulated to stimulate discussion and critical comment. The analysis and conclusions set forth are those of the authors and do not indicate concurrence by other members of the research staff or the Board of Governors. References in publications to the International Finance Discussion Papers Series (other than acknowledgement) should be cleared with the author(s) to protect the tentative character of these papers. Recent IFDPs are available on the Web at www.federalreserve.gov/pubs/ifdp/. This paper can be downloaded without charge from the Social Science Research Network electronic library at www.ssrn.com. 


\title{
Investor Sentiment and the (Discretionary) Accrual-return Relation*
}

\author{
Jiajun Jiang \\ Qi Liu \\ Bo Sun \\ Fudan University \\ Peking University \\ jiangjj@fudan.edu.cn \\ qiliu@gsm.pku.edu.cn \\ Federal Reserve Board \\ bo.sun@frb.gov
}

${ }^{*}$ We are grateful for the comments and suggestions from seminar participants at Peking University, Federal Reserve Board, Midwest Theory Conference, Royal Economic Society, CICF, and EIASM 13th Workshop on Accounting and Economics. Qi Liu acknowledges support by National Natural Science Foundation of China (No. 71502004). The views expressed herein are the authors' and do not necessarily reflect the opinions of the Board of Governors of the Federal Reserve System. 


\title{
Investor Sentiment and the (Discretionary) Accrual-return Relation
}

\begin{abstract}
Discretionary accruals are positively associated with stock returns at the aggregate level but negatively so in the cross section. Using Baker-Wurgler investor sentiment index, we find that a significant presence of sentiment-driven investors is important in accounting for both patterns. We document that the aggregate relation is only prominent during periods of high investor sentiment. Similarly, the cross-section relation is considerably stronger in high-sentiment periods in both economic magnitude and statistical significance. We then embed investor sentiment into a stylized model of earnings management, and illustrate that a positive (negative) relationship between stock returns and earnings management can endogenously emerge in the aggregate (cross section). Our analysis suggests that the (discretionary) accrual-return relation at both the aggregate and firm levels at least partially reflects mispricing that is related to market-wide investor sentiment.
\end{abstract}

Keywords: Investor sentiment, Uncertainty, Earnings management, Accrual anomaly JEL Classifications: D82, D83, G12, G14 


\section{Introduction}

Firms with high discretionary accruals earn abnormally low future returns compared with firms with low discretionary accruals (e.g., Sloan, 1996; Teoh, Welch, and Wong, 1998; and Xie, 2001). Recent studies find that the cross-sectional accrual-return relation can be generalized to the aggregate level but with opposite asset pricing implications. Hirshleifer, Hou, and Teoh (2009) document a strong positive relationship between value-weighted aggregate accruals and future stock market returns. Kang, Liu, and Qi (2010) provide robust evidence that the accrual-return relation at the aggregate level is mainly due to the discretionary component of accruals. The positive relation between discretionary accruals and returns at the aggregate level appears distinct from the negative relation in cross-section. The standard asset pricing models, in which unemotional investors price firms based on the rationally discounted present value of expected future cash flows, have considerable difficulty coherently fitting both patterns.

In an attempt to reconcile these patterns, in this paper we investigate the role of investor sentiment in driving the relationship between discretionary accruals and stock returns. There has been empirical evidence supporting the notion that investor sentiment, broadly defined as a belief about future cash flows that is not justified by the facts at hand, can cause prices to depart from fundamental values, possibly contributing to anomalies (e.g., Baker and Wurgler, 2006,2007; Frazzini and Lamont, 2008; Stambaugh, Yu, and Yuan, 2012). Specific to the accrual-return relation, there is a long-standing debate regarding whether the accrual anomaly reflects market mispricing or compensation for certain risk factor. Against this backdrop, we entertain the possibility that sentiment-

driven mispricing may serve as a partial explanation for the (discretionary) accrual-return relation.

We use Baker-Wurgler investor sentiment index to explore the sentiment effects. The Baker-Wurgler sentiment index is interpreted as increasing with investor optimism or a greater presence of sentiment-driven investors. Strikingly, we find that the positive aggregate relation between discretionary accruals and stock returns is only present, measured by both statistical significance and economic magnitude, during periods of high sentiment. Both full-sample and subsample time-series estimation confirms that the aggregate 
relation is predominantly driven by periods with high investor sentiment. Similarly, in the cross section we find that the accrual anomaly is largely concentrated in high-sentiment periods, although a weak relationship is also observed during periods of low sentiment. Our findings highlight an important role of investor sentiment underlying the (discretionary) accrual-return relation in the data.

Naturally, one would wonder why investor sentiment might contribute to the relationship between discretionary accruals and returns, and perhaps more curiously, how it could lead to opposite asset pricing implications in the time series and cross section. To that end, we embed investor sentiment into a stylized model of earnings management. The one-step departure from the standard model is that investors may over-estimate future cash flows, which captures high investor sentiment in our setup. By switching on and off the measure of investor sentiment, we nest the standard model and make the mechanism transparent.

Investor sentiment, together with an (endogenously generated) "lean-against-the-wind" behavior in the presence of substantial uncertainty about economic fundamentals, gives rise to the positive (discretionary) accrual-return relation in the aggregate in our model. ${ }^{1}$. Managers have greater incentives to inflate earnings for financial gains when the state is bad; meanwhile, stock prices tend to be low, resulting in a negative relation between stock prices and (discretionary) accruals. However, the "lean-against-the-wind" feature alone cannot generate a positive accrual-return relation, because the stock return is also low if low stock prices and high (discretionary) accruals are both driven by low fundamentals. When investors over-estimate payoffs by optimistically assigning a higher weight on discretionary accruals, however, the return becomes negatively related to fundamentals, delivering a positive (discretionary) accrual-return relation in the aggregate.

Guided by our model, we perform additional tests to further examine the role of investor sentiment in the pricing of discretionary accruals in the aggregate. Using the value-weighted average of firm market-to-book ratio as a measure for equity market valuations, we show that during periods of high investor sentiment, market valuation is indeed significantly negatively associated with both aggregate discretionary accruals and market

\footnotetext{
${ }^{1}$ The "lean-against-the-wind" type of manipulation behavior is suggested by Hirshleifer, Hou, and Teoh (2009) and Kang, Liu, and Qi (2010).
} 
returns, leading to a positive association between the two; but this relation is absent when investor sentiment is low.

Our model also suggests that stock returns and the actual amount of earnings management are negatively correlated in the cross section due to firm-level manipulation uncertainty, when the variation in the reporting environment across firms is sufficiently large relative to that in firm productivity (which tends to be driven by common factors such as business cycle fluctuations and technology development). Importantly, investor optimism, captured by a higher weight on discretionary accruals in pricing stocks, significantly exacerbates the accrual anomaly. The model results are consistent with a (weak) pattern of accrual anomaly during low-sentiment periods and a significantly stronger relation when investor sentiment is high.

Taken together, our study provides confirming evidence that the (discretionary) accrualreturn relation at least partially reflects mispricing that is related to market-wide investor sentiment. A large literature examines the (discretionary) accrual-return relation and offers two primary explanations: (i) investors fail to identify the transitory nature of the accruals and implicitly over-react to reported earnings (see, e.g., Sloan, 1996; Xie, 2001; Richardson et al., 2005; Hirshleifer, Hou, and Teoh, 2012) and (ii) higher returns to firms with low accruals are compensation for a certain risk (see, e.g, Ng, 2005; Zhang, 2007; Khan, 2008; Wu, Zhang, and Zhang, 2010). Our approach reveals new evidence for over-pricing of discretionary accruals at both the aggregate and firm levels.

Our analysis is related to prior studies arguing that beliefs of equity market participants share a common time-varying sentiment component and can exert influence on pricing (e.g., DeLong, Shleifer, Summers and Waldmann, 1990; Lee, Shleifer, and Thaler, 1991; Ritter, 1991; Baker and Wurgler, 2006, 2007; Frazzini and Lamont, 2008; Stambaugh, Yu, and Yuan, 2012). The classic critique against sentiment effects is that they would be eliminated by rational investors that exploit arbitrage opportunities. However, impediments to short selling hinder rational traders' ability to exploit overpricing. As a result, the presence of high market-wide sentiment can lead to overpriced investments, while periods of low sentiment is unlikely to be accompanied by substantial under-pricing (e.g., Miller, 1977; Barber and Odean, 2008; Stambaugh, Yu, and Yuan, 2012; Blocher and Ringgenberg, 2016). In this paper we explore sentiment-related overpricing as at least 
a partial explanation for the positive (negative) relationship between stock returns and discretionary accruals documented in the aggregate (cross section).

The remainder of the paper is organized as follows. We present empirical evidence that investor sentiment plays a key role in accounting for the (discretionary) accrualreturn relation in both aggregate and firm levels. We then build a model of investor sentiment and earnings management in Section 3 and offer an analysis towards reconciling the (discretionary) accrual-return relation in the time series and cross section in Section 4. Section 5 concludes.

\section{Sentiment and accrual-return relation}

\subsection{Investor sentiment}

We measure investor sentiment using the market-based sentiment series constructed by Baker and Wurgler (2006). Baker and Wurgler (2006) define investor sentiment as the propensity to speculate, and they also interpret their index as capturing investor optimism about stocks in general. The sentiment index starts from July 1965 through December 2018, which is the sample we analyze in this paper.

The composite index is estimated by taking the first principal component of five measures of investor sentiment. ${ }^{2}$ The first principal component analysis removes idiosyncratic noises in the five metrics and captures their common, time-varying component. The five metrics considered in their construction include the closed-end fund discount, the number and the first-day returns of IPOs, the equity share in total new issues, and the dividend premium. To address concerns that each of these proxies for sentiment might contain common information about economic fundamentals, Baker and Wurgler (2006) orthogonalize each of the proxies to the NBER recession dummy, growth in consumer durables, non-durables and services as well as growth in the industrial production index prior to performing the principal components analysis.

The sentiment index captures the anecdotal accounts of bubbles and crashes, and it mirrors the fluctuation in a series of speculative episodes well. For example, it exhibits

\footnotetext{
${ }^{2}$ The original paper uses six measures, and the updated series, available on http://people.stern.nyu.edu/jwurgler/, is noted to be estimated using fix measures.
} 
spikes during the 1968-1969 electronics bubble, the biotech bubble of the early 1980s, and the Internet bubble of early 2000s.

Numerous studies have considered the possibility that investor sentiment can exert material influence on pricing. On important component of the argument is that shortsale impediments present the key obstacle to traders seeking to exploit mispricing, so that overpricing cannot be fully eliminated in markets with a significant presence of sentimentdriven investors. As a result, overpricing can occur for many stocks during periods of high investor sentiment, while underpricing is unlikely when investor sentiment is low. We explore the possibility that overpricing of discretionary accruals associated with high investor sentiment could attribute to the (discretionary) accrual-return relation in the data.

\section{$2.2 \quad$ Aggregate relation}

At the aggregate level, we follow Hirshleifer, Hou, and Teoh (2009) and Kang, Liu, and Qi (2010) to construct time-series measures of aggregate stock returns and discretionary accruals. Specifically, we use monthly returns on the CRSP value-weighted market index in excess of the one-month T-bill rate as aggregate stock returns. Annual returns of year $t$ are constructed by compounding monthly returns from May of year $t$ to April of year $t+1$. Following Kang, Liu, and Qi (2010), we construct aggregate discretionary accruals and normal accruals as value-weighted average of firm-level discretionary accruals and normal accruals, respectively. We use time-series Jones (1991) model to decompose accruals at the firm level. We also include in the regression a set of standard control variables. Column 1 and Column 5 of Table 1 replicate the results in Kang, Liu, and Qi (2010). There is a positive relation between aggregate discretionary accruals and future market returns, while normal accruals have little predictive power.

To examine the role of investor sentiment, we compute the average monthly sentiment index in each calender year and split our sample into two high-sentiment and low-sentiment subsamples. In both subsamples, we estimate a regression of future market returns on aggregate discretionary accruals, with and without a set of standard control variables. Hirshleifer, Hou, and Teoh (2009) suggest that such regressions may suffer from the smallsample bias (Nelson and Kim, 1993; Pontiff and Schall, 1998). To generate $p$-values that 
account for this bias, we follow Pontiff and Schall (1998) to compute the randomized p-values. ${ }^{3}$ As shown in Columns 2-3 and Columns 6-7 of Table 1, the predictive power of discretionary accruals is only significant during periods characterized by high investor sentiment.

To draw more rigorous statistical inference, we construct an indicator variable, Denoted as SENT_HIGH, which equals 1 when the value of investor sentiment index is higher than its full-sample median and equals zero otherwise. We include an interaction term between discretionary accruals (or normal accruals) and the indicator variable in the fullsample regressions (Column 4 and 8). The coefficient of the interaction term is positively significant, and the coefficient of aggregate discretionary accruals becomes substantially smaller and statistically insignificant. This result confirms that the positive relation between discretionary accruals and market returns is primarily concentrated in periods with high investor sentiment.

Our results are robust to including other control variables that have been shown to have predictive power of market returns, such as value-weighted book-to-market ratio, dividend-to-price ratio, default spread (i.e., the difference between the Moody's Baa bond yield and Aaa bond yield), term spread (i.e., the difference between ten- and one-year Treasury constant maturity rates), the one-month T-bill rate, and consumption-wealth ratio, etc.

\subsection{Cross-section relation}

We turn to studying the role of investor sentiment in the cross-section pricing of stocks. Following Fama and French (2008), we delete all the microcap stocks (defined as stocks with market cap below the 20th NYSE percentile) throughout our empirical analysis to ensure that our results are not driven by tiny stocks. ${ }^{4}$ At the end of June in each year,

\footnotetext{
${ }^{3}$ This process creates a series of pseudo-independent variables and returns that have similar time-series properties as the actual series used to test return predictability, but are generated under the null of no predictability. This randomization is conducted for 5000 iterations, and the parameter estimates form an empirical distribution that is used to calculate p-values.

${ }^{4}$ According to Fama and French (2008), though microcaps are on average only about $3 \%$ of the market cap of the NYSE-Amex-NASDAQ universe, they account for about $60 \%$ of the total number of stocks. Moreover, the cross-section dispersion of anomaly variables is largest among microcaps, they typically account for more than $60 \%$ of the stocks in extreme sort portfolios.
} 
Table 1: Market Return and Aggregate Discretionary Accruals

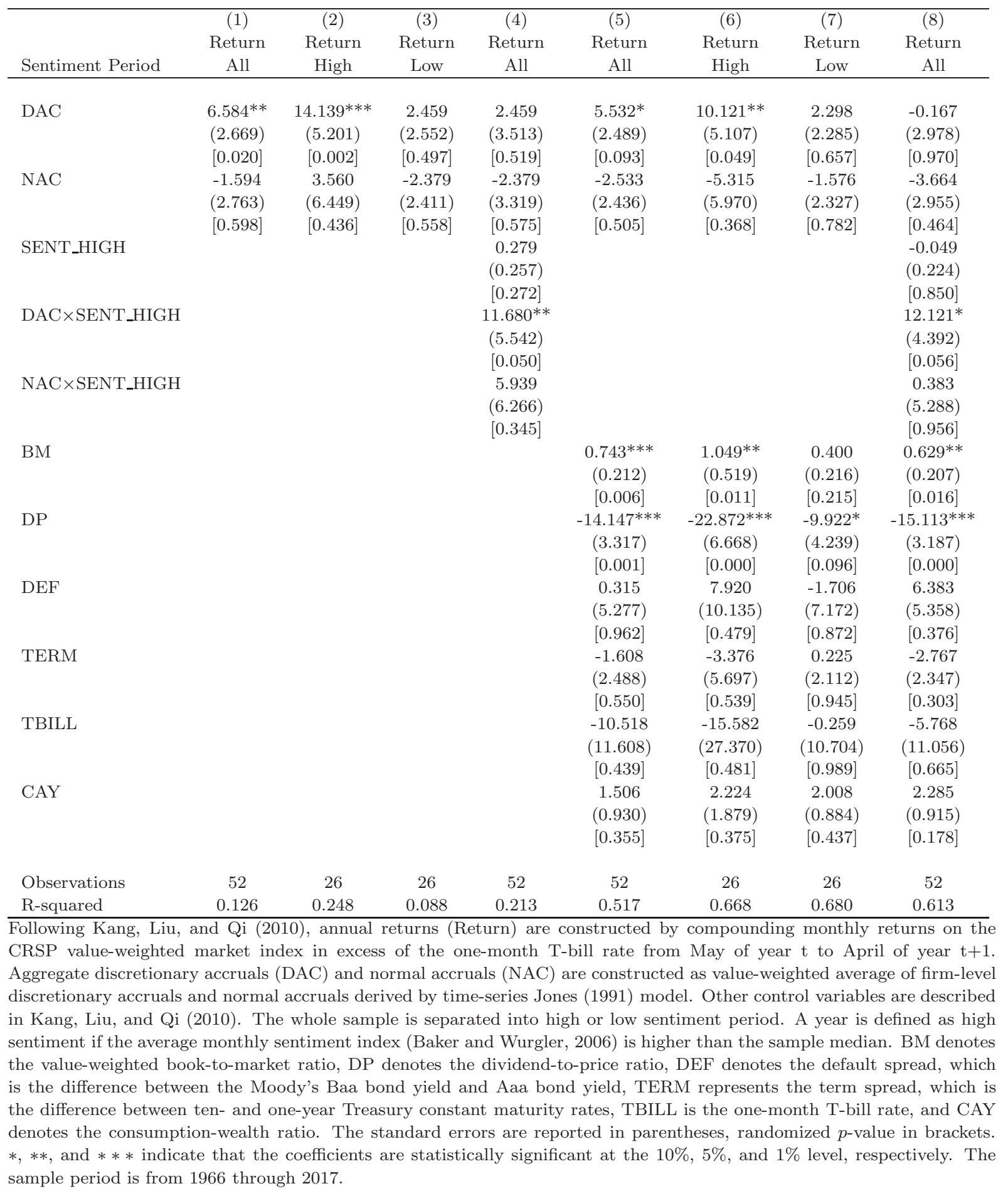


we sort stocks into ten portfolios based on discretionary accruals. Portfolio 1 (10) is the portfolio of stocks with the lowest (highest) discretionary accruals. The results in Panel A of Table 2 show that the average return of portfolio 10 is $0.41 \%$ per month (i.e., $5.12 \%$ annually) lower than that of portfolio 1 . The difference in the FF-4 alphas between portfolio 10 and portfolio 1 is $-0.50 \%$ per month, with a t-statistic of -2.93 . The accrual anomaly documented in the prior literature appears to persist in our sample.

We again split our sample based on the value of investor sentiment. In Panel B of Table 2, we find that the difference in the average return between portfolio 10 and portfolio 1 is $-0.52 \%$ per month with a t-statistic of -2.15 during periods of high sentiment, and $-0.31 \%$ per month during periods of low sentiment but not statistically significant. The difference in the FF-4 alphas between portfolio 10 and portfolio 1 is $-0.57 \%$ per month with a t-statistic of -2.36 during periods of high sentiment, and $-0.36 \%$ per month with a t-statistic of -1.71 during periods of low sentiment. That is, gauged by both economic magnitude and statistical significance, the negative accrual-return relation is largely driven by periods when investor sentiment is high.

Taken together, we document that the aggregate relation between discretionary accruals and returns is concentrated in periods with high investor sentiment, strongly suggesting a behavioral story. In the cross section, the negative relation is weakly present in low-sentiment periods and is significantly stronger in high-sentiment periods, a finding indicating that possibly both a behavioral and a risk-based channel are at work. Motivated by the set of empirical findings, we theoretically explore the role of investor sentiment in driving the (discretionary) accrual-return relation in the next section.

\section{Model}

\subsection{Setup}

We consider a simple one-period economy with a representative firm. The time line of Figure 1 chronicles the sequence of events in the model. The manager runs a firm, whose actual earnings at the end of the period are denoted by $y$, where $y$ is normally distributed with mean $\mu_{y}$ and variance $\sigma_{y}^{2}$. Before the stock is traded, the manager of the firm observes the firm's fundamental $y$. The manager is mandated to publish a report of his 
Table 2: Investor Sentiment and Accrual Anomaly

\begin{tabular}{|c|c|c|c|c|c|c|c|c|c|c|c|}
\hline & 1 & 2 & 3 & 4 & 5 & 6 & 7 & 8 & 9 & 10 & $10-1$ \\
\hline & \multicolumn{11}{|c|}{ A: Full Sample } \\
\hline $\begin{array}{l}\text { Raw } \\
\text { return }\end{array}$ & 1.00 & 1.13 & 1.03 & 1.02 & 0.99 & 0.82 & 0.92 & 0.79 & 0.82 & 0.59 & $\begin{array}{c}-0.41^{* *} \\
{[-2.55]}\end{array}$ \\
\hline FF-4 & $0.18^{*}$ & $0.24^{* *}$ & 0.10 & $0.13^{* *}$ & $0.15^{* *}$ & -0.08 & 0.09 & -0.12 & -0.06 & $-0.32^{* * *}$ & $-0.50 * * *$ \\
\hline \multirow[t]{3}{*}{ alpha } & {$[1.81]$} & {$[2.36]$} & {$[1.28]$} & {$[2.01]$} & {$[2.09]$} & {$[-0.85]$} & {$[1.27]$} & {$[-1.45]$} & {$[-0.68]$} & {$[-2.93]$} & {$[-2.93]$} \\
\hline & \multicolumn{11}{|c|}{ B: Subsample Analysis } \\
\hline & \multicolumn{11}{|c|}{ High Sentiment } \\
\hline $\begin{array}{l}\text { Raw } \\
\text { return }\end{array}$ & 1.09 & 1.22 & 1.12 & 1.18 & 1.07 & 0.83 & 0.89 & 0.77 & 0.85 & 0.57 & $\begin{array}{c}-0.52^{* *} \\
{[-2.15]}\end{array}$ \\
\hline $\mathrm{FF}-4$ & 0.19 & $0.29^{* *}$ & $0.16^{*}$ & $0.24^{* *}$ & 0.16 & -0.12 & 0.02 & -0.16 & -0.05 & $-0.38^{* *}$ & $-0.57^{* *}$ \\
\hline alpha & {$[1.43]$} & {$[2.12]$} & {$[1.70]$} & {$[2.62]$} & [1.44] & {$[-0.78]$} & {$[0.24]$} & {$[-1.26]$} & {$[-0.36]$} & {$[-2.36]$} & {$[-2.36]$} \\
\hline & \multicolumn{11}{|c|}{ Low Sentiment } \\
\hline $\begin{array}{l}\text { Raw } \\
\text { return }\end{array}$ & 0.92 & 1.04 & 0.93 & 0.87 & 0.92 & 0.82 & 0.96 & 0.81 & 0.79 & 0.61 & $\begin{array}{c}-0.31 \\
{[-1.44]}\end{array}$ \\
\hline $\mathrm{FF}-4$ & 0.09 & 0.15 & 0.05 & 0.02 & $0.16^{*}$ & -0.04 & 0.15 & -0.05 & -0.06 & $-0.27^{*}$ & $-0.36^{*}$ \\
\hline alpha & {$[0.61]$} & {$[1.20]$} & {$[0.40]$} & {$[0.24]$} & {$[1.88]$} & {$[-0.50]$} & {$[1.33]$} & {$[-0.58]$} & {$[-0.52]$} & {$[-1.91]$} & {$[-1.71]$} \\
\hline
\end{tabular}

In Panel A, we form the ten value-weighted portfolios at the end of June in each year by sorting stocks by discretionary accruals. Portfolio 1 (10) is the portfolio of stocks with the lowest (highest) discretionary accruals. We report the raw return and the alpha relative to the Fama-French four factor model for each portfolio. In Panel B, we first divide the full sample into two subsamples based on the level of Baker-Wurgler investor sentiment index. Then we repeat the portfolio analysis in Panel A for each subsample. The Newey-West t-statistics with lag 12 are reported in square brackets. $*, * *$, and $* * *$ indicate that the coefficients are statistically significant at the $10 \%, 5 \%$, and $1 \%$ level, respectively. The sample period is from July 1966 through June 2018.

private signal, denoted by $\tilde{s}$, which investors use to make their investment strategies. The difference, denoted by $m=\tilde{s}-y$, is interpreted as the amount of earnings management undertaken by the manager. At the end of the period, actual earnings $y$ are distributed as dividends to investors.

Manager The manager's utility in our model is given by

$$
U^{M}(y, m) \equiv P(y+m)-\delta \tilde{s} m-\frac{1}{2} c(m-k)^{2},
$$

where $p=P(\tilde{s})$ denotes the price of the stock given the report $(\tilde{s})$. The first term reflects the manager's desire to maximize the share price of the firm. Typically, managers prefer higher stock prices because their pay package often contains a substantial equity component. In addition, the second term $\delta \tilde{s} m$ with $\delta>0$ captures the feature that the manager's marginal benefit of earnings manipulation decreases with reported earnings. In reality, firms usually rely on some measures of accounting profits, such as earnings per share (EPS), in their executives' Annual Incentive Plans to determine executive pay. 


\begin{tabular}{|c|c|c|}
\hline $\begin{array}{l}\text { Managers observes } \quad \text { Manager sends out } \\
\text { the actual earnings } y \text { an earnings report } \tilde{s}\end{array}$ & $\begin{array}{l}\text { Investors price } \\
\text { the firm based } \\
\text { on the report } \tilde{s}\end{array}$ & $\begin{array}{l}\text { Earnings } y \text { are } \\
\text { paid to investors }\end{array}$ \\
\hline
\end{tabular}

Figure 1: Model Timeline

Managers receive bonus awards only when EPS is above the threshold pre-specified in the contract, implying a diminishing marginal payoff from earnings management. For analytic tractability, we assume that the marginal benefit of earnings manipulation decreases with reported earnings linearly, a shorthand expression represented by the second term.

Following Dye and Sridhar $(2004,2008)$, we use the third term to denote the cost the manager incurs in adopting a report that is different from the true realization. The random variable $k$ represents some facet of the reporting environment unknown to outsiders that influences the manipulation cost. $k$ is privately observed by the manager, and outside investors only know the distribution of $k$, which is normally distributed $k \sim N\left(\mu_{k}, \sigma_{k}^{2}\right)$ and independent of $y$. The unobserved nature of $k$ implies that investors cannot unambiguously gauge the actual amount of earnings management.

Investors All investors in the economy have preferences exhibiting constant absolute risk aversion (CARA) and have initial wealth $W_{0}$ to invest in the firm's stock and one risk-free asset. The investors' utility is defined as

$$
U^{I}(W) \equiv-\exp (-\gamma W)
$$

where $W$ is investors' terminal wealth and $\gamma>0$ is investors' risk-aversion coefficient. There is a risk-free asset available to investors at no cost. For simplicity, we assume that the risk-free rate is normalized to zero. Thus, investors' wealth constraints are $W_{0}=p q+q_{f}, W=y q+q_{f}$, where $q$ and $q_{f}$ are the investors' demand for the firm's asset and the risk-free asset respectively. In the following, we permit the case where $p<0$, for ease of exposition. Under the assumption of normality and CARA utility, the investors' utility maximization problem becomes:

$$
\max _{q, q_{f}} E\left[U^{I}(W) \mid \tilde{s}\right]=E_{I}[W \mid \tilde{s}]-\gamma \frac{\operatorname{Var}_{I}[W \mid \tilde{s}]}{2},
$$

where $E_{I}[\cdot \mid \tilde{s}]$ is the investors' belief about their expected wealth given the report $\tilde{s}$, and 
$\operatorname{Var}_{I}[\cdot \mid \tilde{s}]$ is the investors' belief about the conditional variance of their wealth given $\tilde{s}$. Motivated by the empirical evidence in Section 2, we allow for the possibility that investor belief about the mean and variance of their wealth can deviate from the true value. The details on investor irrationality will be discussed in Section 3.2. The quantity of stock is normalized to one perfectly divisible share.

\subsection{Earnings management and stock prices}

Now we solve for the model equilibrium in which investors know the probability distributions of $y$ and $k$, but are unable to observe their actual values. Following the literature, we first conjecture that the stock price of the firm is a linear function of reported earnings: $P(\tilde{s})=\alpha+\beta \tilde{s}$. With the conjectured price function, the first-order condition for the manager's problem (1) yields $\beta-c m+c k-\delta y-2 \delta m=0$, and therefore

$$
m=\frac{\beta+c k-\delta y}{c+2 \delta}, \quad \forall y \text {. }
$$

The amount of earnings management, $m$, can be expressed as a function of $y$ and $k$, both random variables. Therefore, $m$ itself is a random variable. Recall that $k$ affects the manager's misreporting cost: when $k$ and $m$ increase by an equal amount, the cost of manipulation remains unchanged, implying that a higher $k$ leads to greater managerial incentives to inflate earnings. As the manager's marginal benefit of manipulation decreases with reported earnings, $m$ is decreasing in $y$.

\section{Equilibrium stock price}

For rational investors who form their belief following Bayes' rule, the mean and variance of final earnings conditional on reports $\tilde{s}$ are derived in Appendix A and are expressed as follows.

$$
E[y \mid \tilde{s}]=\mu_{y}+\frac{\sigma_{y}^{2}}{\sigma_{x}^{2}+\sigma_{y}^{2}}\left(\frac{c+2 \delta}{c+\delta} \tilde{s}-\mu_{y}-\mu_{x}\right), \quad \operatorname{Var}[y \mid \tilde{s}]=\frac{\sigma_{x}^{2} \sigma_{y}^{2}}{\sigma_{x}^{2}+\sigma_{y}^{2}}, \text { where } \mu_{x}=\frac{c \mu_{k}+\beta}{c+\delta}
$$

and $\sigma_{x}^{2}=\frac{c^{2} \sigma_{k}^{2}}{(c+\delta)^{2}}$.

Incorporating the notion of investor sentiment, investor belief about the conditional mean and variance of earnings in our model can deviate from the above formulation. In particular, we introduce investor optimism by assuming that investors may over-react to reported earnings. We denote investors' conditional expectation of true earnings as $E_{I}[y \mid \tilde{s}]=\Delta E[y \mid \tilde{s}]$, where the subscript $I$ refers to investor expectation and $\Delta$ represents 
investor sentiment. If $\Delta>1$, investors assign a higher weight on discretionary accruals and overestimate the firm's payoff. Our results are robust to incorporating investor underor over-estimation of the conditional variance of $y$.

In Appendix B, we solve for the linear equilibrium that involves a reporting strategy, $m$, for the manager, joint with a pricing function, $P(\tilde{s})$, for investors, that satisfies the following conditions: (i) Given the manager's reporting strategy and the pricing rule, investors maximize their expected utility based on their (irrational) belief. (ii) Given the pricing function, the manager's reporting strategy maximizes the utility of the manager. Moreover, (iii) market clearing requires that the stock voluntarily held by investors be equal to the total quantity of the stock 1 . We summarize the results below.

Proposition 1 Suppose that the investors are subject to sentiment in the sense that $E_{I}[y \mid \tilde{s}]=\Delta E[y \mid \tilde{s}]$.

(1) Under earnings management, the equilibrium price of the stock with investor irrationality can be expressed as $P(\tilde{s})=\Delta\left[\mu_{y}+\frac{\sigma_{y}^{2}}{\sigma_{x}^{2}+\sigma_{y}^{2}}\left(\frac{c+2 \delta}{c+\delta} \tilde{s}-\mu_{y}-\mu_{x}\right)\right]-\gamma \frac{\sigma_{x}^{2} \sigma_{y}^{2}}{\sigma_{x}^{2}+\sigma_{y}^{2}}$. where $\mu_{x}=\frac{c \mu_{k}+\beta}{c+\delta}$ and $\sigma_{x}^{2}=\frac{c^{2} \sigma_{k}^{2}}{(c+\delta)^{2}}$. $\alpha, \beta$ are given by Equations (4) and (5).

(2) The amount of earnings management is given $m=\frac{\beta+c k-\delta y}{c+2 \delta}$, which is increasing in $k$ and decreasing in $y$.

\section{Discussions: the accrual-return relation}

Earnings management is being priced in our model, because there are two dimensions of information asymmetry between the manager and investors: the manager possesses private knowledge about productivity $y$ and reporting environment $k$. Financial statements conflate productivity shocks with earnings management in our model, and even fully rational investors cannot perfectly gauge the true state of a firm in equilibrium. As it turns out, relative uncertainty about productivity $y$ and reporting environment $k$ is also crucial in determining the accrual-return relation, which is the subject of this section.

Following the literature (e.g., Easley and O'Hara, 2004; Cao, Wang and Zhang, 2005; Goldstein and Yang, 2017), stock returns in our model is given by $r=y-P(\tilde{s})$. As the empirical literature uses discretionary accruals to proxy for earnings management, 
the theoretical counterpart of the relationship between discretionary accruals and stock returns is given by $\operatorname{Cov}(r, m)$ in our setup.

\subsection{Accrual-return relation at the aggregate level}

A "lean-against-the-wind" behavior of managerial manipulation has been proposed as a candidate explanation for the positive (discretionary) accrual-return relation (Hirshleifer, Hou, and Teoh (2009), Kang, Liu, and Qi (2010)). Our model endogenously delivers the "lean-against-the-wind" behavior, and illustrates that it is likely a necessary but not sufficient condition to account for the aggregate accrual-return relation.

Taking a representative-firm approach, the "lean-against-the-wind" property in the aggregate can emerge endogenously when there is considerable time-series variation in funda-

mentals $y$ (compared to $k$ ). Note that in our model $\operatorname{Cov}(P(\tilde{s}), m)=\frac{\Delta \sigma_{y}^{2}}{\left(\sigma_{x}^{2}+\sigma_{y}^{2}\right)(c+2 \delta)}\left(-\delta \sigma_{y}^{2}+\frac{c^{2} \sigma_{k}^{2}}{c+\delta}\right)$ holds. At the aggregate, if $\delta(c+\delta) \sigma_{y}^{2}>c^{2} \sigma_{k}^{2}$ is satisfied, there is a negative relation between stock price and earnings management. When fundamentals are low, managers have greater incentives to inflate earnings; meanwhile, stock prices are also low, resulting in a negative relation between prices and accrual.

However, the feature of "lean-against-the-wind" alone is not sufficient to generate a positive accrual-return relation at the aggregate level. When low stock price and high level of earnings manipulation are both driven by low fundamentals, the future return is also low, producing a negative relation between return and (discretionary) accruals.

We show that investor sentiment, combined with the "lean-against-the-wind" behavior, can account for the positive (discretionary) accrual-return relation. It is straight-forward to calculate that $\operatorname{Cov}(r, m)=-\frac{\delta}{c+2 \delta} \sigma_{y}^{2}-\frac{\Delta \sigma_{y}^{2}}{\left(\sigma_{x}^{2}+\sigma_{y}^{2}\right)(c+2 \delta)}\left(-\delta \sigma_{y}^{2}+\frac{c^{2} \sigma_{k}^{2}}{c+\delta}\right)$. Thus, $\operatorname{Cov}(r, m)>0$ only if $\delta(c+\delta) \sigma_{y}^{2}>c^{2} \sigma_{k}^{2}$ and $\Delta>\left[1+\frac{\sigma_{x}^{2}}{\sigma_{y}^{2}}\right] /\left[1-\frac{c^{2} \sigma_{k}^{2}}{\sigma_{y}^{2} \delta(c+\delta)}\right]>1$, exhibiting investor optimism. The intuition is as follows. When investors over-estimate firm value possibly by over-reacting to earnings reports, the return will become negatively correlated with underlying productivity $(y)$, delivering a positive accrual-return relation at the aggregate level. This pattern is absent if investors are fully rational: they will correctly allocate a weight (that is less than 1) on reported earnings when pricing the stock, and the return is consequently positively correlated with productivity $y$; as earnings management is decreasing in $y$, the (discretionary) accrual-return relation cannot be positive. 
Our model suggests that the positive accrual-return relation should be only present during periods of investor optimism when investor sentiment is high $(\Delta>1)$. As we are interpreting our model as a representative-firm framework in order to shed light on the aggregate pattern, the condition for the positive relation is that uncertainty about productivity $(y)$ dominates that about reporting environment $(k)$ in the time series. As aggregate productivity fluctuates constantly due to business cycles and technology development, whereas the aggregate reporting environment is governed by accounting standards and governance rules, whose changes are slow-moving in nature, we think the condition that there is sufficient variation in $y$ relative to $k$ likely holds in the aggregate. We provide more empirical validation in the rest of this section.

Corollary 1 Suppose that $\delta(c+\delta) \sigma_{y}^{2}>c^{2} \sigma_{k}^{2}$.

(1) $\operatorname{Cov}(P, m)<0$ and $\frac{\partial \operatorname{Cov}(P, m)}{\partial \Delta}<0$, suggesting that there is a "lean-against-thewind" property, which is stronger in periods when investor sentiment is high.

(2) $\operatorname{Cov}(r, m)>0$ only if $\Delta>\left[1+\frac{\sigma_{x}^{2}}{\sigma_{y}^{2}}\right] /\left[1-\frac{c^{2} \sigma_{k}^{2}}{\sigma_{y}^{2} \delta(c+\delta)}\right]>1$. Moreover, $\frac{\partial \operatorname{Cov}(r, m)}{\partial \Delta}>$ 0 , suggesting that the positive accrual-return relation at the aggregate level is concentrated in periods when investor sentiment is high.

In addition to the patterns shown in Table 1, we conduct the following test to further gauge the empirical relevance of our theory. We divide the sample into high-sentiment and low-sentiment subsamples using the median level of investor sentiment as the cutoff. Using the aggregate market-to-book ratio as a measure for equity market valuations, we show in Table 3 that during periods of high sentiment, market valuation is indeed significantly negatively correlated with both aggregate discretionary accruals and market returns, giving rise to a positive association between the two; but this pattern does not exist when market sentiment is low. In fact, during periods of low sentiment, the correlation between market valuations and market returns is positive (though not significant), consistent with our model prediction that in a market dominated by rational pricing, low market valuations are driven by low fundamentals, which also imply low future returns. Thus, the positive accrual-return relation at the aggregate level is absent during periods of low sentiment. 
Table 3: Market-to-Book Ratio and Aggregate Discretionary Accruals

\begin{tabular}{lcc}
\hline Sentiment Period & $\begin{array}{c}\text { High } \\
\mathrm{M} / \mathrm{B}\end{array}$ & $\begin{array}{c}\text { Low } \\
\mathrm{M} / \mathrm{B}\end{array}$ \\
\hline \multirow{3}{*}{ Return } & & \\
& $-0.346^{*}$ & 0.143 \\
DAC & {$[0.083]$} & {$[0.486]$} \\
& $-0.569^{* * *}$ & -0.266 \\
& {$[0.002]$} & {$[0.190]$} \\
\hline
\end{tabular}

The market-to-book ratio (M/B) is calculated as the value-weighted average of firm-level market-to-book ratio, which is the sum of the firm's market value of equity and book value of total liabilities, divided by the book value of total assets. Following Kang, Liu, and Qi (2010), annual returns (Return) are constructed by compounding monthly returns on the CRSP value-weighted market index in excess of the one-month T-bill rate from May of year $t$ to April of year $t+1$. Aggregate discretionary accruals (DAC) are constructed as value-weighted average of firm-level discretionary accruals. The sample is separated into high or low sentiment periods. A year is defined as high sentiment if the average monthly sentiment index (Baker and Wurgler, 2006) is higher than the sample median. The table reports the Pearson's correlation coefficient and the standard $p$-value in brackets. $*, * *$, and $* * *$ indicate that the coefficients are statistically significant at the $10 \%, 5 \%$, and $1 \%$ level, respectively. The sample period is from 1966 through 2017.

\subsection{Accrual-return relation in the cross-section}

The relative uncertainty about productivity and reporting environment may have rather different properties at the individual firm level. While firm productivity tends to be driven by common factors such as business cycles and technology advancement, the personal cost involved for a manager to manipulate earnings is subject to internal control systems and managerial characteristics that vary substantially in the cross section. It is natural to stipulate that substantial uncertainty about managerial manipulation cost (relative to productivity) exists at the firm level. In that case, the relationship between stock returns and the amount of earnings management becomes negative.

Corollary 2 Suppose that $\delta(c+\delta) \sigma_{y}^{2}<c^{2} \sigma_{k}^{2}$. Then $\operatorname{Cov}(r, m)<0$ and $\frac{\partial \operatorname{Cov}(r, m)}{\partial \Delta}<0$, suggesting that the negative accrual-return relation in the cross-section is stronger during periods when investor sentiment is high.

Consistent with what we find in Table 2, the negative relation can exist in the cross section and is magnified during periods of high investor sentiment. As investors can only 
subtract the expected amount of earnings management when pricing the stock, stock returns and the actual amount of earnings management are negatively correlated in the cross section due to the firm-level manipulation uncertainty. Investor optimism leads investors to assign a higher weight on reported earnings (and hence discretionary accruals), exacerbating the negative relation.

So far in this section we show that the accrual-return relation depends on the variation of $y$ relative to that of $k$. When uncertainty about productivity is substantial (relative to that about the reporting environment), the accrual-return relation can be positive; otherwise, it is negative. Thus, it is natural to expect that the amplification effect of investor sentiment on the positive accrual-return relation at the aggregate level (driven by high investor sentiment) is concentrated in periods when productivity uncertainty is high, and in contrast, the amplification effect of investor sentiment on the negative accrual-return relation in the cross section is concentrated in periods when productivity uncertainty is low. We provide consistent evidence in Appendix C.

\section{Conclusion}

By studying the role of investor sentiment, we offer an analysis toward reconciling the (discretionary) accrual-return relation in the aggregate and at the firm level. Empirically, we document coherent patterns that investor sentiment is likely an important driver of the (discretionary) accrual-return relation. Guided by a model with investor sentiment, we find that the "lean-against-the-wind" behavior of earnings management is indeed important, though not sufficient, to generate the aggregate positive relationship between returns and discretionary accruals. Investor sentiment plays a key role here, and the positive accrual-return relation is only significant during periods of high investor sentiment. In addition, the negative accrual-return relation in the cross-section is also primarily driven by high-sentiment periods.

Our study provides confirming evidence that the (discretionary) accrual-return relation at least partially reflects mispricing that is related to market-wide investor sentiment. To that end, our approach reveals new evidence for over-pricing of discretionary accruals at both the aggregate and firm levels. Certainly more work lies ahead to develop a richer 
understanding of the role investor sentiment plays in pricing accruals.

\section{References}

[1] Arya, A., J. Glover, and S. Sunder. (1998). "Earnings Management and the Revelation Principle," Review of Accounting Studies, 3: 7-34.

[2] Baker, M., Wurgler, J. (2006). "Investor Sentiment and the Cross-section of Stock Returns," Journal of Finance, 61, $1645 ? 680$.

[3] Ball, R., Gerakos, J., Linnainmaa, J. T. and Nikolaev, V., 2016. "Accruals, Cash Flows, and Operating Profitability in the Cross Section of Stock Returns," Journal of Financial Economics, 121, 28-45.

[4] Baker, M., Wurgler,J. (2007). "Investor Sentiment in the Stock Market," Journal of Economic Perspectives, 21, $129 ? 51$.

[5] Banerjee, A. (1992). "A Simple Model of Herd Behavior," Quarterly Journal of Economics, 107: 797-817.

[6] Bulkley, G. and R. Harris (1997). "Irrational Analysts' Expectations as a Cause of Excess Volatility in Stock Prices?" Economic Journal, 107: 359-371.

[7] Cao, H., T. Wang, and H. Zhang. (2005) "Model Uncertainty, Limited Market Participation, and Asset Prices," Review of Financial Studies, 18, 1219-1251.

[8] Cen, L., H. Lu, and L. Yang. (2012) "Investor Sentiment, Disagreement, and BreadthReturn Relationship," Management Science, 59, 1076-1091.

[9] Claessens, S., S. Djankov, J. Fan, and L. Lang (2002). "Disentangling the Incentive and Entrenchment Effects of Large shareholdings," Journal of Finance, 57: 2741-2772.

[10] Cornett M. M, A. J. Marcus, H. Tehranian (2008). "Corporate Governance and Pay-for-performance: The Impact of Earnings Management," Journal of Financial Economics, 87(2), 357-373.

[11] Dechow, P.M., Sloan, R.G., Sweeney, A.P., (1996). "Causes and Consequences of Earnings Manipulation: An Analysis of Firms Subject to Enforcement Actions by the SEC," Contemporary Accounting Research, 13, 1-36. 
[12] Demski, J. (1998) "Performance Measure Manipulation," Contemporary Accounting Research, 15: 261-85.

[13] Dye, R. (1988) "Earnings Management in an Overlapping Generations Model," Journal of Accounting Research, 26 : 195-235.

[14] Dye, R. and S.S. Sridhar (2004) "Reliability-Relevance Trade-Offs and the Efficiency of Aggregation," Journal of Accounting Research, 42 : 51-88.

[15] Dye, R. and S.S. Sridhar (2008) "A Positive Theory of Flexibility in Accounting Standards," Journal of Accounting and Economics, 46 : 312-333.

[16] Easley, D. and M. O'Hara (2004) "Information and the Cost of Capital," Journal of Finance, 59 : 1553-1583.

[17] Evans, J.H. and S.S. Sridhar (1996) "Multiple Control Systems, Accrual Accounting, and Earnings Management," Journal of Accounting Research, 34: 45-65.

[18] Fama, E. F. and K. R. French. (2008) "Dissecting Anomalies," Journal of Finance, 63: $1653-1678$.

[19] Fischer, P. E. and R. E. Verrecchia. (2000) "Reporting Bias," Accounting Review, 75: 229-245.

[20] Glover, J., Y. Ijiri, C. Levine, and P. Liang. (2005). "Verifiability and Manipulability vs. Robustness to Information Asymmetries about Verifiability and Manipulability," Carnegie Mellon University Working Paper.

[21] Goldman, E. and S. L. Slezak. (2006). "An Equilibrium Model of Incentive Contracts in the Presence of Information Manipulation," Journal of Financial Economics 80, 603-626.

[22] Goldstein, I and L. Yang. (2015). "Information Diversity and Complementarities in Trading and Information Acquisition," Journal of Finance, 70, 1723-1765.

[23] Goldstein, I and L. Yang. (2017). "Information Disclosure in Financial Markets," Annual Review of Financial Economics, 9, 101-125. 
[24] Guttman, I., O. Kadan, and E. Kandel. (2006). "A Rational Expectations Theory of Kinks in Financial Reporting," Accounting Review, 81(4): 811-848.

[25] Guo H. and X. W. Jiang. (2011). "Accruals and the Conditional Equity Premium," Journal of Accounting Research, 49(1): 187-221.

[26] Healy, P. M. and J. M. Wahlen. (1999). "A Review of the Earnings Management Literature and its Implications for Standard Setting," Accounting Horizon, 13: 365383.

[27] He W., L. Ng, N. Zaiats, and B. Zhang (2012). "Do Dividends Signal Earnings Manipulation?" University of New South Wales Working Paper

[28] Hirshleifer, D., K. Hou, and S. Teoh. "Accruals, Cash Flows, and Aggregate Stock Returns. Journal of Financial Economics, 91: 389-406.

[29] Kang, Q., Q. Liu, and R. Qi (2010). "Predicting Stock Market Returns with Aggregate Discretionary Accruals," Journal of Accounting Research, 48: 815-858.

[30] La Porta, R., F. Lopez-de-Silanes, A. Shleifer, and R. Vishny. (1998). "Law and Finance," Journal of Political Economy, 106: 1113-1155.

[31] LeRoy, S. and R. Porter. (1981). "The Present Value Relation: Tests Based on Variance Bounds," Econometrica, 49: 555-574.

[32] Leuz, C., D, Nanda, and P. D. Wysocki. (2003). "Earnings Management and Investor protection: An International Comparison," Journal of Financial Economics, 69: 505527.

[33] Mankiw, G. and S. Zeldes. (1991). "The Consumption of Stockholders and Nonstockholders," Journal of Financial Economics, 29: 97-112.

[34] Indjejikian, R., H. Lu, and L. Yang. (2014). "Rational Information Leakage," Management Science, 60, 2762-2775.

[35] Riley, J. G. (1979). "Informational Equilibrium," Econometrica, 47: 331-359.

[36] Stambaugh, R. F., Yu, J., and Yuan, Y. (2012). "The Short of it: Investor Sentiment and Anomalies," Journal of Financial Economics, 104(2), 288-302. 
[37] Sloan, R.G., (1996). "Do Stock Prices Fully Reflect Information in Accruals and Cash Flows about Future Earnings?" The Accounting Review, 71: 289-315.

[38] Xie, H. (2001). "The Mispricing of Abnormal Accruals," The Accounting Review, 76: $357-373$. 


\section{A Conditional mean and variance of $y$}

Note that $\tilde{s}=y+\frac{\beta+c k-\delta y}{c+2 \delta}=\frac{c+\delta}{c+2 \delta} y+\frac{\beta+c k}{c+2 \delta}$. Define $s=\frac{c+2 \delta}{c+\delta} \tilde{s}=y+x$, where $x=\frac{\beta+c k}{c+\delta}$ is independent of $y$, normally distributed with mean $\mu_{x}=\frac{\beta+c \mu_{k}}{c+\delta}$ and variance $\sigma_{x}^{2}=\frac{c^{2} \sigma_{k}^{2}}{(c+\delta)^{2}}$. Then observing $\tilde{s}$ is equivalent to observing $s$, since $\frac{c+2 \delta}{c+\delta}$ is a known constant. Define $U=\frac{y+x-\mu_{y}-\mu_{x}}{\sqrt{\sigma_{x}^{2}+\sigma_{y}^{2}}}$. Then $U$ is standard normal, and $s=\mu_{s}+\sigma_{s} U$ where $\mu_{s}=\mu_{y}+\mu_{x}$ and $\sigma_{s}=\sqrt{\sigma_{x}^{2}+\sigma_{y}^{2}}$. Meanwhile, $y$ can be written as $y=\mu_{y}+\sigma_{y}\left(\rho U+\sqrt{1-\rho^{2}} V\right)$, where $\rho=\frac{\sigma_{y}}{\sqrt{\sigma_{x}^{2}+\sigma_{y}^{2}}}$. It is easy to check that $V$ is standard normal and $\operatorname{Cov}(U, V)=0$ (thus, $U$ and $V$ are independent). Now it is straight-forward to calculate that

$$
\begin{aligned}
E[y \mid \tilde{s}] & =E[y \mid s]=E\left[\mu_{y}+\sigma_{y}\left(\rho U+\sqrt{1-\rho^{2}} V\right) \mid U\right]=\mu_{y}+\sigma_{y} \rho U \\
& =\mu_{y}+\frac{\sigma_{y}^{2}}{\sigma_{x}^{2}+\sigma_{y}^{2}}\left(s-\mu_{y}-\mu_{x}\right)=\mu_{y}+\frac{\sigma_{y}^{2}}{\sigma_{x}^{2}+\sigma_{y}^{2}}\left(\frac{c+2 \delta}{c+\delta} \tilde{s}-\mu_{y}-\mu_{x}\right), \\
\operatorname{Var}[y \mid \tilde{s}] & =\operatorname{Var}[y \mid s]=\operatorname{Var}\left[\mu_{y}+\sigma_{y}\left(\rho U+\sqrt{1-\rho^{2}} V\right) \mid U\right]=\sigma_{y}^{2}\left(1-\rho^{2}\right)=\frac{\sigma_{x}^{2} \sigma_{y}^{2}}{\sigma_{x}^{2}+\sigma_{y}^{2}} .
\end{aligned}
$$

\section{B Solving the equilibrium price}

Given the manager's reporting strategy $m$, we solve the investors' investment problem, and check whether the equilibrium value of $p$ is in fact linear in $\tilde{s}$ as conjectured. Investors form their expectation of the future wealth as follows:

$$
\begin{aligned}
E_{I}[W \mid \tilde{s}] & =E_{I}[y \mid \tilde{s}] q+q_{f}=\Delta\left[\mu_{y}+\frac{\sigma_{y}^{2}}{\sigma_{x}^{2}+\sigma_{y}^{2}}\left(\frac{c+2 \delta}{c+\delta} \tilde{s}-\mu_{y}-\mu_{x}\right)\right] q+\left(W_{0}-p q\right), \\
\operatorname{Var}_{I}[W \mid \tilde{s}] & =\operatorname{Var}_{I}[y \mid \tilde{s}] q^{2}=\frac{\sigma_{x}^{2} \sigma_{y}^{2}}{\sigma_{x}^{2}+\sigma_{y}^{2}} q^{2} .
\end{aligned}
$$

Substituting these into investors' objective function (2), the investors' problem is given by

$$
\max _{q} \Delta\left[\mu_{y}+\frac{\sigma_{y}^{2}}{\sigma_{x}^{2}+\sigma_{y}^{2}}\left(\frac{c+2 \delta}{c+\delta} \tilde{s}-\mu_{y}-\mu_{x}\right)\right] q+\left(W_{0}-p q\right)-\frac{\gamma}{2} \frac{\sigma_{x}^{2} \sigma_{y}^{2}}{\sigma_{x}^{2}+\sigma_{y}^{2}} q^{2} .
$$

The optimization problem of investors can be characterized by the following first-order condition: $\Delta\left[\mu_{y}+\frac{\sigma_{y}^{2}}{\sigma_{x}^{2}+\sigma_{y}^{2}}\left(\frac{c+2 \delta}{c+\delta} \tilde{s}-\mu_{y}-\mu_{x}\right)\right]-p-\gamma \frac{\sigma_{x}^{2} \sigma_{y}^{2}}{\sigma_{x}^{2}+\sigma_{y}^{2}} q=0$.

When the market clears, the optimal share of the stock investors are willing to hold must be equal to the quantity of stock available, which is normalized to 1. Equating the market demand to 1 , we obtain the equilibrium stock price:

$$
P(\tilde{s})=\Delta\left[\mu_{y}+\frac{\sigma_{y}^{2}}{\sigma_{x}^{2}+\sigma_{y}^{2}}\left(\frac{c+2 \delta}{c+\delta} \tilde{s}-\mu_{y}-\mu_{x}\right)\right]-\gamma \frac{\sigma_{x}^{2} \sigma_{y}^{2}}{\sigma_{x}^{2}+\sigma_{y}^{2}} .
$$


Therefore, the price is in fact linear in $\tilde{s}$, and matching the coefficients with the conjecture $P(\tilde{s})=\alpha+\beta \tilde{s}$ yields that

$$
\begin{aligned}
\alpha & =\Delta\left[\mu_{y}-\frac{\sigma_{y}^{2}}{\sigma_{x}^{2}+\sigma_{y}^{2}}\left(\mu_{y}+\mu_{x}\right)\right]-\gamma \frac{\sigma_{x}^{2} \sigma_{y}^{2}}{\sigma_{x}^{2}+\sigma_{y}^{2}}, \\
\beta & =\frac{\Delta \sigma_{y}^{2}}{\sigma_{x}^{2}+\sigma_{y}^{2}} \frac{c+2 \delta}{c+\delta}>0,
\end{aligned}
$$

\section{Additional implications and tests}

We show in this paper that the accrual-return relation depends on the variation of $y$ relative to that of $k$. When uncertainty about productivity is substantial (relative to that about the reporting environment), the accrual-return relation can be positive; otherwise, it is negative. Thus, it is natural to expect that the amplification effect of investor sentiment on the positive accrual-return relation at the aggregate level (driven by high investor sentiment) is concentrated in periods when productivity uncertainty is high, formalized below.

Corollary $3 \frac{\partial \operatorname{Cov}(r, m)}{\partial \Delta}>0$ if and only if $\delta(c+\delta) \sigma_{y}^{2}>c^{2} \sigma_{k}^{2}$.

To empirically test this prediction, we use the economic uncertainty index data from Jurado, Ludvigson and $\mathrm{Ng}$ (2015) (hereafter JLN) to proxy for uncertainty in $y$ in the aggregate. The economic uncertainty index is constructed from information contained in hundreds of macroeconomic indicators with monthly frequency. We calculate the average of 1-month ahead uncertainty index in a year, and then separate the sample into highuncertainty and low-uncertainty periods using the median value as the threshold. As shown in Table 4, at the aggregate level, we find that the coefficient of the interaction term between sentiment and discretionary accruals (DAC $\times$ SENT_HIGH) is 14.94 with a t-statistic of 2.84 (randomized p-value is 0.07) during high-uncertainty periods. But this coefficient is only 4.27 with a t-statistic of 0.31 (randomized p-value is 0.85 ) during low-uncertainty periods.

It is useful to clarify that in our setting uncertainty about productivity at the aggregate is reasonably proxied by JLN economic uncertainty index, while the counterpart at the firm level should be measured by dispersion in productivity across firms. As there is no direct measure of dispersion in firm-level true earnings available to us, we also use JLN 
Table 4: Uncertainty, Investor Sentiment, and Aggregate Accrual-return Relation

\begin{tabular}{lcc}
\hline Uncertainty Period & $\begin{array}{c}\text { Return } \\
\text { High }\end{array}$ & $\begin{array}{c}\text { Return } \\
\text { Low }\end{array}$ \\
\hline \multirow{2}{*}{ DAC } & 0.872 & 11.865 \\
& $(3.283)$ & $(12.811)$ \\
NAC & {$[0.870]$} & {$[0.545]$} \\
& -4.142 & -8.126 \\
& $(3.016)$ & $(13.517)$ \\
SENT_HIGH & {$[0.501]$} & {$[0.560]$} \\
& 0.322 & -0.304 \\
DAC $\times$ SENT_HIGH & $(0.301)$ & $(0.719)$ \\
& {$[0.413]$} & {$[0.644]$} \\
NAC $\times$ SENT_HIGH & $(5.284)$ & 4.272 \\
& {$[0.071]$} & {$[0.847]$} \\
& $(6.603)$ & -6.232 \\
Controls & {$[0.380]$} & {$[0.712]$} \\
Observations & Yes & Yes \\
R-squared & 26 & 26 \\
\hline & 0.757 & 0.759 \\
\hline
\end{tabular}

We divide the sample into high- and low-uncertainty periods based on economic uncertainty index data from Jurado, Ludvigson and Ng (2015). In each subsample, we perform the time series tests similar to Column 8 in Table 1. All the variables are defined in Table 1. The standard errors are reported in parentheses, randomized $p$-value in brackets. $*, * *$, and $* * *$ indicate that the coefficients are statistically significant at the $10 \%, 5 \%$, and $1 \%$ level, respectively. The sample period is from 1966 through 2017.

economic uncertainty to gauge firm-level dispersion - it has been argued that dispersion in firm-level productivity tends to be high during periods of high aggregate uncertainty (Bloom, 2014).

In the cross-section, we divide the sample into four subsamples, based on JLN economic uncertainty and investor sentiment, shown in Table 5. We find that the amplification effect of sentiment on the negative accrual-return relation only appears in periods of low economic uncertainty. That is, the difference-in-difference FF-4 alpha returns between the high-sentiment and low-sentiment groups is only statistically significant during periods of low uncertainty. The subsample results in Table 5 again confirms that high investor sentiment is an important driver of the accrual anomaly in the cross section. 
Table 5: Uncertainty, Investor Sentiment and Accrual Anomaly

\begin{tabular}{|c|c|c|c|c|c|c|c|c|c|c|c|}
\hline & 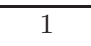 & 2 & 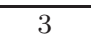 & $\overline{4}$ & $\overline{5}$ & 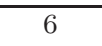 & $\overline{77}$ & 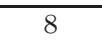 & 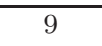 & 10 & $10-1$ \\
\hline & \multicolumn{11}{|c|}{ A. Raw Return: Sorted by Uncertainty and Sentiment } \\
\hline Low unc low sent & 1.22 & 1.18 & 1.04 & 0.83 & 0.99 & 1.04 & 1.02 & 1.11 & 1.23 & 1.05 & $\begin{array}{c}-0.18 \\
{[-0.52]}\end{array}$ \\
\hline Low unc high sent & 1.07 & 1.38 & 1.15 & 1.12 & 1.22 & 1.02 & 0.81 & 0.80 & 0.81 & 0.41 & $\begin{array}{l}-0.66^{*} \\
{[-1.85]}\end{array}$ \\
\hline High-Low sent & & & & & & & & & & & $\begin{array}{l}-0.48 \\
{[-0.97]}\end{array}$ \\
\hline High unc low sent & 0.73 & 0.96 & 0.87 & 0.90 & 0.87 & 0.68 & 0.92 & 0.62 & 0.52 & 0.34 & $\begin{array}{c}-0.38 \\
{[-1.40]}\end{array}$ \\
\hline High unc high sent & 1.13 & 0.95 & 1.06 & 1.26 & 0.82 & 0.53 & 1.00 & 0.73 & 0.93 & 0.82 & $\begin{array}{l}-0.31 \\
{[-1.20]}\end{array}$ \\
\hline \multirow[t]{2}{*}{ High-Low sent } & & & & & & & & & & & $\begin{array}{c}0.07 \\
{[0.19]}\end{array}$ \\
\hline & \multicolumn{11}{|c|}{ B. FF-4 Alpha: Sorted by Uncertainty and Sentiment } \\
\hline Low unc low sent & $\begin{array}{c}0.10 \\
{[0.66]}\end{array}$ & $\begin{array}{c}0.11 \\
{[0.88]}\end{array}$ & $\begin{array}{c}0.11 \\
{[0.91]}\end{array}$ & $\begin{array}{c}-0.16 \\
{[-1.40]}\end{array}$ & $\begin{array}{c}0.05 \\
{[0.61]}\end{array}$ & $\begin{array}{c}0.00 \\
{[0.03]}\end{array}$ & $\begin{array}{c}-0.04 \\
{[-0.36]}\end{array}$ & $\begin{array}{c}0.07 \\
{[0.57]}\end{array}$ & $\begin{array}{l}0.19^{*} \\
{[1.80]}\end{array}$ & $\begin{array}{c}0.20 \\
{[1.38]}\end{array}$ & $\begin{array}{c}0.10 \\
{[0.38]}\end{array}$ \\
\hline Low unc high sent & $\begin{array}{c}0.16 \\
{[1.08]}\end{array}$ & $\begin{array}{c}0.50^{* * *} \\
{[3.10]}\end{array}$ & $\begin{array}{l}0.23^{*} \\
{[1.95]}\end{array}$ & $\begin{array}{c}0.21 \\
{[1.63]}\end{array}$ & $\begin{array}{l}0.28^{* *} \\
{[2.42]}\end{array}$ & $\begin{array}{c}0.08 \\
{[0.86]}\end{array}$ & $\begin{array}{c}0.02 \\
{[0.16]}\end{array}$ & $\begin{array}{c}-0.11 \\
{[-0.80]}\end{array}$ & $\begin{array}{l}-0.06 \\
{[-0.52]}\end{array}$ & $\begin{array}{c}-0.50^{* *} \\
{[-2.48]}\end{array}$ & $\begin{array}{r}-0.66^{* *} \\
{[-2.18]}\end{array}$ \\
\hline High-Low sent & & & & & & & & & & & $\begin{array}{r}-0.75^{* *} \\
{[-1.98]}\end{array}$ \\
\hline High unc low sent & $\begin{array}{l}-0.01 \\
{[-0.03]}\end{array}$ & $\begin{array}{c}0.12 \\
{[0.65]}\end{array}$ & $\begin{array}{c}0.06 \\
{[0.32]}\end{array}$ & $\begin{array}{c}0.18 \\
{[1.41]}\end{array}$ & $\begin{array}{l}0.25^{* *} \\
{[2.05]}\end{array}$ & $\begin{array}{l}-0.12 \\
{[-1.13]}\end{array}$ & $\begin{array}{c}0.28 \\
{[1.70]}\end{array}$ & $\begin{array}{l}-0.09 \\
{[-0.68]}\end{array}$ & $\begin{array}{l}-0.14 \\
{[-0.87]}\end{array}$ & $\begin{array}{c}-0.45^{* *} \\
{[-2.31]}\end{array}$ & $\begin{array}{l}-0.44 \\
{[-1.49]}\end{array}$ \\
\hline High unc high sent & $\begin{array}{c}0.24 \\
{[1.28]}\end{array}$ & $\begin{array}{l}-0.08 \\
{[-0.40]}\end{array}$ & $\begin{array}{c}0.00 \\
{[0.00]}\end{array}$ & $\begin{array}{c}0.31^{* *} \\
{[2.02]}\end{array}$ & $\begin{array}{l}-0.02 \\
{[-0.12]}\end{array}$ & $\begin{array}{l}-0.45 \\
{[-1.38]}\end{array}$ & $\begin{array}{l}-0.03 \\
{[-0.17]}\end{array}$ & $\begin{array}{l}-0.28 \\
{[-1.65]}\end{array}$ & $\begin{array}{l}-0.08 \\
{[-0.49]}\end{array}$ & $\begin{array}{l}-0.20 \\
{[-0.88]}\end{array}$ & $\begin{array}{l}-0.44 \\
{[-1.44]}\end{array}$ \\
\hline High-Low sent & & & & & & & & & & & $\begin{array}{c}0.00 \\
{[0.00]}\end{array}$ \\
\hline
\end{tabular}

At the end of June in each year, we sort stocks into four groups based on uncertainty and sentiment. In each group, we form the ten value-weighted portfolios by sorting stocks by discretionary accruals. Portfolio 1 (10) is the portfolio of stocks with the lowest (highest) discretionary accruals. We report the raw return and the alpha relative to the Fama-French four factor model for each portfolio. The NeweyWest t-statistics with lag 12 are reported in square brackets. $*, * *$, and $* * *$ indicate that the coefficients are statistically significant at the $10 \%, 5 \%$, and $1 \%$ level, respectively. The sample period is July 1966 to June 2018. 